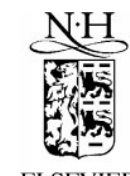

ELSEVIER

\title{
Growth and the relativity of satisfaction
}

\author{
David de la Croix* \\ National Fund for Scientific Research and Université catholique de Louvain, Place Montesquieu 3, \\ B-1348 Louvain-la-Neuve, Belgium
}

Received 13 August 1996; received in revised form 31 October 1997; accepted 31 October 1997

\begin{abstract}
We extend Ramsey's model to be in accordance with the facts that self-reported levels of satisfaction are almost unrelated to economic prosperity, both across countries and across time. We assume that things are judged by the extent to which they depart from social norms. Norms are based on the past experience of agents. A special case is when norms are built on the basis of the best previous experience. Agents do not internalize their own effect on social norms and the competitive equilibrium is sub-optimal. The dynamics display oscillations and a slow speed of adjustment or path dependency. An optimal solution can be decentralized by a planner by means of capital taxation along the adjustment path. Finally, fiscal policy is shown to display substantial transitory effects. (C) 1998 Elsevier Science B.V. All rights reserved.
\end{abstract}

Keywords: Consumption; Social norms; Modified golden rule; Habit formation; Optimal taxation JEL classification: $\mathrm{O} 40$

\section{Introduction}

Neo-classical growth theory (e.g. Cass, 1965; Ramsey, 1928) suggests that utility increases with consumption and, as a consequence, with wealth. Accepting that satisfaction and instantaneous utility are equivalent, this implies that the rich should feel more satisfied than the poor, that reported satisfaction levels should be higher in more developed countries and that satisfaction should grow in line with wealth. As a matter of fact, only the first of these three consequences of standard models seems to be weakly verified.

\footnotetext{
*E-mail: delacroix@ires.ucl.ac.be
} 
Following various studies, international differences in satisfaction are very small and almost unrelated to economic prosperity. ${ }^{1}$ Fig. 1 displays the results of a survey undertaken by Gallup which simply consisted of asking a question on people's satisfaction in different parts of the world. "These are some puzzles about these results. Why are the impoverished Latin Americans so satisfied? Are Europeans really less happy than Americans and Australians?" (Argyle, 1987, p. 103). ${ }^{2}$

The Gallup type studies give useful information on the non-existence of the simple link consumption $\rightarrow$ utility only if satisfaction levels are comparable across countries, i.e. if the preference orderings are identical. If this is not the case, one has to use a method that is robust to cultural discrepancies and, possibly also, to other sources of bias such as translation problems. Such a study has been carried out by Cantril (1965) and further analysed by Easterlin (1974). People were asked to imagine the best possible life and the worst possible life they could lead. They then had to say where their present life fell on a scale of $0-10$. The results are presented in Fig. 2: "The inference about a positive association (between wealth and satisfaction) relies heavily on the observations for India and the USA. (... ) the values for Cuba and the Dominican Republic reflects unusual political circumstances. ( . . . ) there is not much evidence, for these ten countries ${ }^{3}$ of a systematic association between income and happiness. (...) a similar lack of association would be found between happiness and other economic magnitudes such as income inequality." (Easterlin, 1974, pp. 105-106). Even if the methods and concepts of happiness studies are subject to criticism, one conclusion is that there is no evidence at the aggregate level in favour of the idea that wealth buys satisfaction.

Despite continually rising prosperity in the developed countries, there were considerable fluctuations in the percentage of those who said they were very satisfied. In Fig. 3

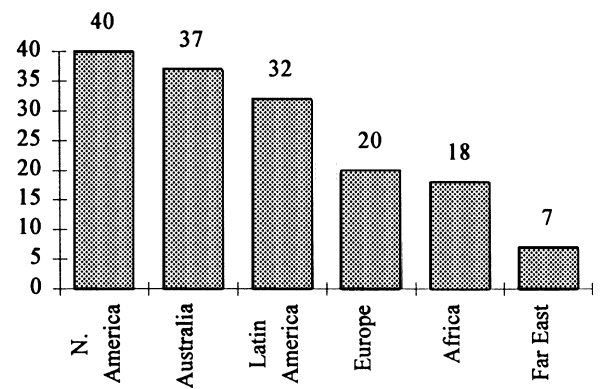

Fig. 1. Percentages "very happy" (following Argyle, 1987, p. 103).

\footnotetext{
${ }^{1}$ This conclusion of various aggregate studies is sometimes contradicted by panel data analysis, such as in Veenhoven (1994).

${ }^{2}$ A second study of the Gallup type comforts the idea that there is no positive association between wealth and satisfaction. "The results are ambiguous. The four lowest income countries are neither at the top nor at the bottom of the table" (Easterlin, 1974, p. 108). Another useful source for making international comparisons of satisfaction is the survey carried out twice a year in the EEC (European Commission). The inference about a positive association between wealth and satisfaction relies heavily on the observations for two countries, Denmark and Greece. The other eight countries do not display any clear association.

${ }^{3}$ Nigeria, Egypt, Philippines, Panama, Brazil, Yugoslavia, Japan, Poland, Israel, West Germany.
} 


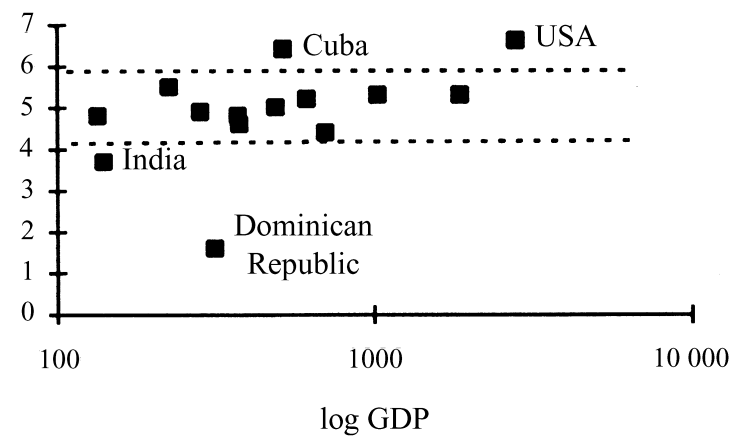

Fig. 2. Personal happiness rating and GDP per head, 14 countries, ca. 1960 (following Easterlin, 1974).

we compare the US data gathered by Veenhoven (1993) with EEC data from the Euro-barometer. The observed fluctuations for the USA and the astonishing constancy for EEC 10 data are two puzzles which standard models are confronted with.

Existing models of growth cannot account for the non-relation between wealth and satisfaction as they have adopted a very naive approach to the determination of utility. As stressed by Frank (1989), there is a lack of context: "The neoclassical economic model of choice abstracts from context, saying that utility depends only on the level of consumption. ( . . ) one must not only know the relevent levels of consumption, but also have an appropriate frame of reference within which to evaluate them." Except for a few general papers of the late seventies (Ng, 1978, 1980; Scitovsky, 1976; Silver, 1980) and some applied research on job saitsfaction, ${ }^{4}$ no attention has been paid to the determinants

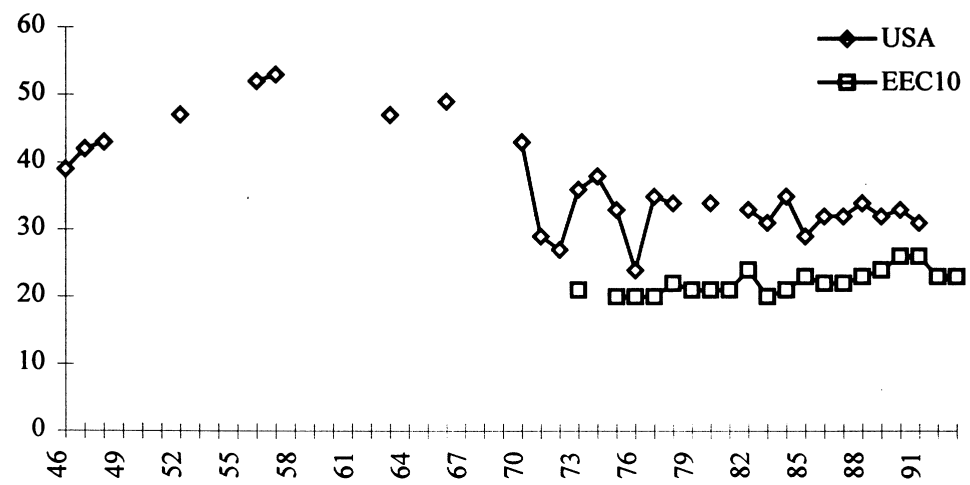

Fig. 3. Percentages 'very happy' over time (following Veenhoven (1993), Eurobarometer, 1994).

\footnotetext{
${ }^{4}$ See for instance Clark and Oswald (1996): "The first finding of the paper is that workers' reported levels of well-being are at best weakly correlated with absolute income. Its second, and central, finding is that measures of relative and comparative income are significantly correlated with reported levels of happiness at work."
} 
of satisfaction. The aim of our research is to amend the standard Ramsey model by introducing a few more "frames of reference" and so to improve the modeling of satisfaction.

One possible frame of reference is people's aspiration and/or norm. According to Michalos (1980), "the hypothesis regarding satisfaction as a function of the gap between aspiration and achievement has been almost uniformly succesful." Norms are fed by (real and/or imaginary) comparisons with one's own and with other persons' past. The studies of Michalos (1980) conclude, on the basis of questionnaire data, that comparisons with the most-liked previous experience and with a reference group of other people are the main factors of the norm/achievement gap and, hence, of satisfaction. Using the terminology of Scitovsky (1976), the "enjoyment of novelty" may come from comparisons with the past, and "satisfaction of status" from comparisons with other people. ${ }^{5}$

The above studies make the hypothesis that things are judged by the extent to which they depart from a baseline of past experiences. Experiences that are salient or extreme and relevant to other experiences imply important changes in instantaneous satisfaction. However, another important aspect of satisfaction is that, "gradually, the most positive events will cease to have impact as they themselves are absorbed into the new baseline against which further events are judged (Brickman et al., 1978).

A central aspect of our research is based on the assumption that norms are fundamentally collective. Using the terminology of Becker (1996), this means that norms are part of the social (vs personal) capital of the agents. The future norms of the society are formed from the current and past consumption choices of its members. Each individual member does not internalize the effect of his current choice on social norms and thus on his future tastes.

The paper is organized as follows. In Section 2, we set up the norm-achievement model in a dynamic general equilibrium and analyse some properties of the steady state. Dynamic aspects are then considered, including the special case of comparisons with the previous best experience. Section 3 is devoted to the role of the government and to the choice of optimal tax rates. Section 4 concludes.

\section{The norm-achievement gap model}

The economy is composed by a continuum of identical individuals uniformly

\footnotetext{
${ }^{5}$ The idea that agents compare their income (or their spendings) with some prior standard and with other persons was initiated by Duesenberry (1949) in his relative income hypothesis. The habit formation side of his model has been used in empirical studies of consumer behaviour (see Ferber, 1973 for a survey) and, more scarcely, to model union behaviour (Kotowitz and Portes, 1974; de la Croix et al., 1996). General equilibrium studies of these phenomena are provided in Ryder and Heal (1973) and Wan (1970).

${ }^{6}$ This is a consequence of adaptation, a theory developed by biologists and psychologists, "which is a mechanism for acquainting us with changes in the environment. If the same stimulation continues, adaptation gradually counteracts its effects to the point where it may no longer be sensed or its quality becomes neutral" (Helson, 1964). The power of adaptation has been explored by Brickman et al. (1978). They show that quadriplegic patients are just as satisfied some time after their accident as other people. The impact of their accident is completely eroded by an habituation process.
} 
distributed over the interval [0,1]. Individuals, indexed by $i$, have an infinite lifetime. They supply one unit of labor inelastically per unit of time to production. One good is produced by firms using capital and labor under constant returns to scale. It can either be consumed or added to the capital stock. The resource constraint of the economy is:

$$
c_{t} \leq f\left(k_{t}\right)+(1-\delta) k_{t}-k_{t+1}
$$

where $f$ is the intensive production function that maps capital per worker into output per worker, with $f_{1}>0$ and $f_{11}<0 . k_{t}$ denotes the capital stock and $\delta \in[0,1]$ the depreciation rate. Aggregate consumption is given by:

$$
c_{t}=\int_{0}^{1} c_{i t} \mathrm{~d} i
$$

According to the norm-achievement gap theory, the satisfaction of each household is greater when its achievements are close to (or even greater than) norms, lower when they fall short. The simplest way to model this relativity of satisfaction is to define the instantaneous utility function $u$ as depending both on actual purchases of goods $c_{i t}$ and social norms $s_{t}$ :

$$
u\left(c_{i t}, s_{t}\right)
$$

with $u_{1}>0, u_{2}<0, u$ is concave. ${ }^{8}$ As $s_{t}$ is an aggregate variable, it reflects the life standards of the society as a whole.

The function $n$ describes how social norms are built:

$$
s_{t+1}=n\left(s_{t}, c_{t}\right)
$$

The partial derivatives of $n$ are $n_{1} \geq 0, n_{2} \geq 0, n$ is convex. The function $n$ incorporates the important elements mentioned above: it describes how norms are a function of the past experience of the members of the society and how the impact of past consumption is eroded by an habituation process. ${ }^{9}$ Let us consider in turn the intertemporal competitive equilibrium and the centrally planned equilibrium.

\subsection{The intertemporal competitive equilibrium}

In the competitive economy, factor prices equal marginal productivities:

$$
\begin{aligned}
& w_{t}=f\left(k_{t}\right)-k_{t} f_{1}\left(k_{t}\right) \\
& r_{t}=f_{1}\left(k_{t}\right)-\delta
\end{aligned}
$$

Each household chooses wealth $b_{i t+1}$ and consumption $c_{i t}$ so as to maximise its lifetime utility function subject to the budget constraint:

\footnotetext{
${ }^{7}$ The alternative assumption of finitely-lived agents is also interesting: in that case, the preferences of children could be affected by the consumption pattern of their parents. If parents are not altruistic, the resulting equilibrium is sub-optimal owing to the inter-generational externality. This case is analysed in de la Croix (1996) and de la Croix and Michel (1997).

${ }^{8}$ If we call $s_{t}$ the level of habits, special cases proposed in the literature on habit formation are $u\left(c_{t}-s_{t}\right)$ (Ferson and Constantinides, 1991) and $u\left(c_{t} / s_{t}\right)$ (Abel, 1990). $\mathrm{Ng}(1980)$ proposes $u\left(c_{t}, c_{t} / s_{t}\right)$.

${ }^{9}$ In the literature on habits, $n$ is in general linear. An exception is in Campbell and Cochrane (1995).
} 


$$
\begin{aligned}
& \max \sum_{t=s}^{\infty} \theta^{t-s} u\left(c_{i t}, \bar{s}_{t}\right) \\
& \text { s.t. } c_{i t}=\left(1+r_{t}\right) b_{i t}+w_{t}-b_{i t+1}
\end{aligned}
$$

and to the initial conditions $b_{i 0}=\underline{b} .\left\{\bar{s}_{t}\right\}_{t=s}^{\infty}$ represents the future sequence of norms. Because of perfect foresight, this sequence is known to the agent. $b_{i t}$ denotes the net financial wealth of individual $i$, with $\int_{0}^{1} b_{i t} \mathrm{~d} i=k_{t}$ at equilibrium. $\left.\theta \in\right] 0,1[$ is the subjective discount rate.

Denoting by $\mu_{t}$ the shadow price of financial wealth, the equilibrium path should satisfy:

$$
\begin{aligned}
& u_{1}\left(c_{i t}, \bar{s}_{t}\right)=\mu_{t} \\
& \mu_{t}=\theta \mu_{t+1}\left(r_{t}+1\right)
\end{aligned}
$$

in addition to the transversality condition $\lim _{t \rightarrow \infty}\left[\theta^{t} u_{1}\left(c_{i t}, \bar{s}_{t}\right) b_{i t}\right]=0$. At the symmetric equilibrium, the conditions can be rewritten replacing $c_{i t}$ by $c_{t}$ and $b_{i t}$ by $k_{t}$. The Euler equation is similar to the one of the Ramsey model except that preferences are endogeneously changing over time. This endogenous change results from the evolution of social norms.

The above system is not yet autonomous because of the dependence on the exogenously given path $\left\{\bar{s}_{t}\right\}_{t=s}^{\infty}$. But after substitution of $\bar{s}_{t}$ by the law of evolution of $s_{t}$ given by Eq. (4), the system Eq. (8) - Eq. (9) - Eq. (10) - Eq. (4) can be used to describe the equilibrium solution. This is in fact true as long as the fixed-point property of the infinite sequence of $s_{t}$ holds. The idea of inserting an equilibrium condition into a first-order condition in an infinite horizon dynamic model with externalities is discussed at length by Romer (1989).

Notice that, because individuals are atomistic, they coordinate in order to take the effect of current consumption on norms (and, hence, on future tastes) into account. There is thus a "taste" externality which implies that the competitive equilibrium is not a first best solution. It is important to stress that there is no contradiction between the presence of this externality and the fact that the dynamic path of future norms is correctly anticipated by the non-myopic ${ }^{10}$ consumers. As usual in models with perfect foresight, they are indeed aware of the functioning of the economy. However, without cooperation with all other consumers, they have to treat norms as exogenously given. ${ }^{11}$ The equilibrium solution is described by the resource constraint Eq. (1), by the rule Eq. (4)

\footnotetext{
${ }^{10}$ See $\mathrm{Ng}$ and Wang (1993) for a model with myopia and concern for relative income.

${ }^{11}$ An alternative way to model the role of norms would be to replace the perfect foresight hypothesis by adaptative expectations enriched or not by some learning mechanism. However, we prefer here to take the standard growth model as a benchmark and to clearly distinguish our framework with externalities from models in which expectations are not rational. Moreover, adaptative expectations in our context would lead to substantial time consistency problems in the sense that the optimal plan chosen at time $t$ will no longer be optimal at time $t+1$. This problem cannot be solved without introducing ad-hoc assumptions. See Elster (1979).
} 
and by the first order conditions of the household programme Eq. (9) - Eq. (10). Using Eqs. (6) and (10), the Modified Golden Rule holds at steady state:

$$
1 / \theta=f_{1}(\tilde{k})+1-\delta
$$

Steady state consumption is given by $\tilde{c}=f(\tilde{k})-\delta \tilde{k}$ and steady state norms by $\tilde{s}=$ $n(\tilde{s}, \tilde{c})$. The steady state is unique. The dynamics are analysed by linearizing the system around the steady state. The computations are presented in Appendix A. For the dynamic system to yield a unique stable trajectory one needs one eigenvalue larger than one (corresponding to the anticipated variable $c$ ) and two eigenvalues lower than one (corresponding to the two predetermined variables $k$ and $s$ ). From an inspection of the expression in Appendix A, it is clear that the dynamic analysis is quite less trivial than in the corresponding Ramsey problem. Two derivatives play a central role: $u_{12}$ and $n_{2}$. Let us analyse the following special cases:

\subsubsection{Special case 1: $u_{12}=0$}

The derivative $u_{12}$ measures the effect of social norms on the desire for consumption. It is very likely that $u_{12}$ is positive so that an increase in norms increases the marginal utility of consumption (a distaste effect of social norms is not excluded a priori but is very unlikely). When $u_{12}=0$, utility is separable in consumption and norms and the endogeneous changes in social norms do not modify the marginal utility of consumption. As a consequence, marginal utilities are no longer affected by norms and the dynamics are similar to the ones of the Ramsey model: the eigenvalues are always real and the dynamics are always characterized by a saddle-path.

\subsubsection{Special case 2: $n_{2}=1$}

When $n_{2}=1$, norms follow a non-stationnary process. Not surprisingly, one eigenvalue is 1 so that norms display path dependency. Looking at the two other eigenvalues, it is clear that if $u_{12}$ is large enough, one will have complex values generating oscillatory behaviour.

On the basis of these two special cases, the intertemporal competitive equilibrium with norms may display oscillatory behaviour if a rise in norms increases sufficiently the desire for consumption. If $u_{12}$ is arbitrarily close to 0 the equilibrium path converges to the one of Ramsey's model.

It is now interesting to derive a condition under which a uniformly maintained increase in consumption does not affect the steady-state utility, so that the model is no longer in contradiction with the facts mentioned in the introduction. To make sense, one should add that this uniformly maintained increase in consumption is made possible e.g. by an additive positive technological shift in the production function. A sufficient condition is: ${ }^{12}$

\footnotetext{
${ }^{12}$ Proposition 1 derives a condition under which the hypothesis defended by Easterlin (1995) is verified, i.e. that "the material norms on which judgments of well-being are based increase in the same proportion as the actual income of the society."
} 
Proposition 1. If

$$
n_{1}(\tilde{s}, \tilde{c})+n_{2}(\tilde{s}, \tilde{c}) \frac{\left|u_{2}(\tilde{c}, \tilde{s})\right|}{u_{1}(\tilde{c}, \tilde{s})}=1,
$$

a uniformly maintained increase in consumption does not increase steady state utility.

Proof: Computing $\mathrm{d} u(\tilde{c}, \tilde{s}) / \mathrm{d} \tilde{c}$ by linearizing $\mathrm{u}$ and $\mathrm{g}$ around $(\tilde{c}, \tilde{s})$ leads to

$$
\frac{\mathrm{d} u(\tilde{c}, \tilde{s})}{\mathrm{d} \tilde{c}}=1-n_{1}(\tilde{s}, \tilde{c})-n_{2}(\tilde{s}, \tilde{c}) \frac{\left|u_{2}(\tilde{c}, \tilde{s})\right|}{u_{1}(c, \tilde{s})}
$$

The interpretation of this proposition is not straightforward as it embeds different types of special cases. If, for instance, $u(c, s)=u(c-s)$, one needs $n_{1}(\tilde{s}, \tilde{c})+n_{2}(\tilde{s}, \tilde{c})=1$ to obtain the result. If $u(c, s)=u(c / s)$, a linear norm rule is sufficient: In this case steady-state consumption is a fixed proportion of steady state norms: $\tilde{c}=\left(1-n_{1}\right) / n_{2} \tilde{s}$. A linear rule is standard in empirical studies of habit formation (see for instance Ferson and Constantinides, 1991). Moreover, if $n_{1}=0$, norms cover only one past period, and the model describes a consumer interested in the level of consumption and in its growth. A similar model has been studied by Frank and Hutchens (1993) in a finite horizon set-up.

\subsection{The centrally planned equilibrium}

To find the first-best solution of the norm-achievement gap model, we solve the planification problem. The planner chooses $k_{t+1}, s_{t+1}$ and $c_{t}$ so as to maximise the lifetime utility function of the representative household Eq. (7) subject to Eq. (1) and Eq. (4) and to the initial conditions $k_{0}=\underline{k}$ and $s_{0}=\underline{s}$. Denoting the shadow price of social norms (i.e. the Lagrange multiplier associated with the constraint Eq. (4)) by $\lambda_{t}$ and the shadow price of capital by $\mu_{t}$, the equilibrium path should satisfy:

$$
\begin{aligned}
& u_{1}\left(c_{t}^{*}, s_{t}^{*}\right)-\lambda_{t}^{*} n_{2}\left(s_{t}^{*}, c_{t}^{*}\right)=\mu_{t}^{*} \\
& \lambda_{t}^{*}=\theta\left(\lambda_{t+1}^{*} n_{1}\left(s_{t+1}^{*}, c_{t+1}^{*}\right)-u_{2}\left(c_{t+1}^{*}, s_{t+1}^{*}\right)\right) \\
& \mu_{t}^{*}=\theta_{t+1}^{*} \mu_{t+1}^{*}\left(f_{1}\left(k_{t+1}^{*}\right)+1-\delta\right)
\end{aligned}
$$

in addition to Eq. (1), Eq. (4), $k_{0}^{*}=\underline{k}, s_{0}^{*}=\underline{s}$ and the two following transversality conditions: $\lim _{t \rightarrow \infty}\left[\theta^{t} u_{1}\left(c_{t}^{*}, s_{t}^{*}\right) k_{t}^{*}\right]=0$ and $\lim _{t \rightarrow \infty}\left[\theta^{\bar{t}} \lambda^{*}{ }_{t}\right]=0$. A steady state $\left[\tilde{s}^{*}, \tilde{c}^{*}, \tilde{k}^{*}, \tilde{\lambda}^{*}\right]$ should satisfy:

$$
1 / \theta=f_{1}\left(\tilde{k}^{*}\right)+1-\delta
$$

or

$$
1 / \theta=n_{1}\left(\tilde{s}^{*}, \tilde{c}^{*}\right)+n_{2}\left(\tilde{s}^{*}, \tilde{c}^{*}\right) \frac{\left|u_{2}\left(\tilde{c}^{*}, \tilde{s}^{*}\right)\right|}{u_{1}\left(\tilde{c}^{*}, \tilde{s}^{*}\right)}
$$

and

$$
\tilde{\lambda}^{*}=-\theta u_{2}\left(\tilde{c}^{*}, \tilde{s}^{*}\right) /\left(1-\theta n_{1}\left(\tilde{s}^{*}, \tilde{c}^{*}\right)\right)
$$


in addition to $\tilde{c}^{*}=f\left(\tilde{k}^{*}\right)-\delta \tilde{k}^{*}$ and $\tilde{s}^{*}=n\left(\tilde{s}^{*}, \tilde{c}^{*}\right)$. This economy displays two types of steady states that we analyse in turn. A comparable analysis is made by Ryder and Heal (1973) with a linear rule $n$.

Proposition 2. If the shadow price of capital is positive at steady state, the Modified Golden Rule holds.

Proof: If $\mu^{*}$ is positive, $n_{1}+n_{2}\left|u_{2}\right| / u_{1} \neq 1 / \theta$, and Eq. (16) cannot hold. There is only one steady state characterised by Eq. (15). In this case, the Modified Golden Rule is satisfied.

Although some relativity has been introduced in the utility of the consumer, the optimal steady state capital stock is not necessarily different from the standard model. Sufficient conditions for Proposition 2 to hold are $n_{1}(s, c)+n_{2}(s, c) \leq 1$ and $\left|u_{2}\right| \leq u_{1} \forall s$, $c>0$. These two sufficient conditions impose that future norms cannot increase more than proportionally to past consumption levels and that the marginal disutility of norms is not larger than the marginal utility of consumption.

Proposition 3. If the shadow price of capital is zero, the marginal utility of a temporary increase in consumption is zero (satiation equilibrium).

Proof: An equilibrium with satiation exists if the resource constraint is not binding and if

$$
\sum_{t=0}^{\infty} \theta^{t}\left[u\left(c_{t}, s_{t}\right)+\lambda_{t}\left(s_{t+1}-n\left(s_{t}, c_{t}\right)\right)\right]
$$

is maximized. Computing the first order condition of this problem and finding its steady state, one retrieves Eq. (16).

The steady state characterized by Eq. (16) displays satiation. In this case, the planner is indifferent between accepting and rejecting a marginal increment in production. The economy operates below its resource constraint and there is "abundance" of capital. As stressed by Ryder and Heal (1973), such a solution is ruled out in the conventional optimal growth model by the assumption that $u^{\prime}(c)>0$ for finite $c$. In the present model, it is more plausible to permit the total welfare impact of an increment in consumption to be zero, because there are costs to offset against the benefits of an increase in consumption. Notice also that such an equilibrium is not necessarily unique. A detailed analysis of the dynamics with a linear $n$ is provided in Ryder and Heal (1973).

\subsection{The dynamics of social norms: an example}

The linearization of the model around the steady state and the computation of its eigenvalues yield complicated expressions. Moreover, interesting of the model is the non-linear nature of the rule Eq. (4). Linearizing the decision rules could deserve the very nature of the model. For these two reasons, we propose to preserve the non-linear 
nature of the decisions rules and to investigate the dynamic properties of our model with an example. We give specific functional forms to the general functions and simulate calibrated versions of the model.

The utility function chosen displays constant absolute risk aversion:

$$
u\left(c_{t}-s_{t}\right)=\frac{-1}{\alpha} e^{-\alpha\left(c_{t}-s_{t}\right)}
$$

with $\alpha$ being the coefficient of absolute risk aversion, $-u_{11} / u_{1}$. With this specific utility function, changes in public spending have no effect on capital accumulation in the standard Ramsey model (see Blanchard and Fischer, 1989, chap 2). The production function is Cobb-Douglas: $f\left(k_{t}\right)=\beta k_{t}^{\gamma}$, with $\beta>0,0<\gamma<1$. The rule Eq. (4) has a CES form:

$$
n\left(s_{t}, c_{t}\right)=\left(1 / 2 s_{t}^{\rho}+1 / 2 c_{t}^{\rho}\right)^{1 / \rho}
$$

with $\rho \geq 1$. The interest of Eq. (19) is twofold. First, it is a very simple expression involving only one parameter to calibrate. Second, it embeds two interesting special cases: if $\rho=1$ the aspiration rule is linear and the model is a usual habit formation model. When $\rho \rightarrow \infty$ the aspiration rule tends to $\max \left[s_{t}, c_{t}\right]$ and comparisons are made with respect to the best previous experience.

Note that with Eqs. (18) and (19), the steady state of the planification problem is always of the Modified Golden Rule type and the satiation equilibrium can never arise.

The resolution of the dynamic model relies on a Newton-Raphson relaxation method proposed by Laffargue (1990) and Boucekkine (1995) for solving dynamic nonlinear models with perfect foresight. The details of the method are provided in Appendix B. As Boucekkine (1995) shows, this method allows to characterise the nature of the dynamics of the model (explosivity, saddle-point trajectory or infinite number of stable solutions) without having to linearise it and to compute the eigenvalues of the linearised system. Using his criterium, we have checked that our model is characterized by a saddle-path for all chosen parametrisations.

We also analyse the dynamic response of the model to unanticipated exogenous shifts in the parameters. To do so, we compare the optimal response in the presence of norms (CPE - centrally planned equilibrium), the response of the decentralized economy in the presence of norms (ICE - intertemporal competitive equilibrium) and the response of the standard Ramsey model. The numerical values of the parameters have been fixed to $\delta=0.025, \alpha=1, \gamma=0.25, \beta=0.6, \theta=0.99$.

Some information can already be drawn from the changes in the values of the eigenvalues of the linearized system as a function of $\rho$ : In the standard Ramsey model, the dynamic system is of dimension two, the eigenvalues are always real numbers, and are here equal to 0.94 and 1.07. With norms, the dynamic system of the planner's problem is of dimension four. When $\rho=5$, the four eigenvalues are complex conjugate and are equal to $0.97 \pm 0.033 \mathrm{i}$ and $1.04 \pm 0.035 \mathrm{i}$. If $\rho$ is increased to 100 , the eigenvalues become $0.988 \pm 0.016 \mathrm{i}$ and $1.02 \pm 0.017 \mathrm{i}$. From these values, it is clear that adjustment takes more time in the optimal norm-achievement gap model than in the Ramsey model 
and that one may observe oscillations, because the eigenvalues are complex numbers. Moreover, an increase in $\rho$ makes the economy more sluggish in adjusting. ${ }^{13}$

The simulation of a permanent productivity increase (shift in $\beta$ ) is presented in Fig. 4a,b. The dotted line represents the solution for the standard Ramsey model, the solid line the one of the CPE and the bold line the one of the ICE.

Comparing CPE with Ramsey, the optimal consumption profile is steeper in the model with norms, consumption attains a maximum and then declines slowly (asymmetric hump). Expansion of consumption is quick and contraction is slow. Both consumption and capital overshoot their new steady state value and converge with damped oscillations. If one increases the value of $\rho$ (the results are not reported here), the variability in the capital stock is increased and its overshooting may last a very long time. The simulation of a negative shift in productivity (not reported here) shows that the model displays little asymmetry, at least when $\theta$ is high. We next simulate the same shift when $\rho$ is higher and $\theta$ lower. The frequency of oscillations in consumption and capital increases (Fig. 4b). ${ }^{14}$ The asymmetric hump of the previous simulations is repeated through time with declining amplitude. As the planner attaches some weight to consumption growth per se, he prefers steep increases in consumption and flat decreases. When $\theta$ is low, the future consequences of increasing norms and thus the future requirements are not too important, so that short-run consumption increases are favoured. Note also that the effect on the capital stock is very important, and that the short-run increase is far more important than the long-run increase. The difference between achievements and norms, which determines the instantaneous satisfaction level, is also plotted. We conclude that the satisfaction path, in the face of productivity shifts, does not mimic the consumption path. For instance, with $\{\rho=5, \theta=.99\}$ in the CPE case, the peak in satisfaction is in period 1 and the peak in consumption in period 60 .

Comparing CPE with ICE: It is clear that in the absence of a tax policy, the household will increase consumption more than is optimal, given that it does not internalize the effect of its consumption rush on social norms. The fluctuations in its instantaneous satisfaction are also more important compared to the CPE.

\subsection{Comparison with the best previous experience}

Following Michalos (1980), the best previous experience, together with comparisons with "the average folk", are found to be the main determinant of aspirations and of the goal-achievement gap, which itself explains quite well the reported levels of satisfaction. His study is carried out over twelve specific domains (e.g. health, family life etc.) and his conclusion seems rather robust. When comparisons are made with the best previous experience, the function Eq. (4) is of the form:

\footnotetext{
${ }^{13}$ A further application of these results could be useful for the following problem: it is well known that the convergence speed of the basic Ramsey model is too high with respect to the empirical evidence (Barro and Sala-I-Martin, 1995, chapter 2) and that the the actual time required for substantial convergence is typically of the order of several generations. The simulations we propose will show that the model with social norms generates more reasonable convergence speeds (or even, no convergence at all).

${ }^{14}$ Our experience shows that, with a low $\theta$, some asymmetry appears.
} 
(a)

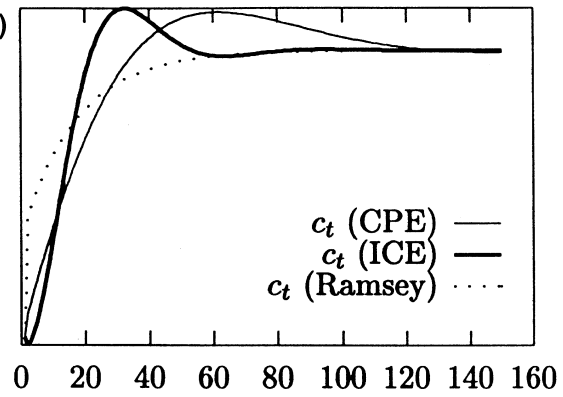

(b)

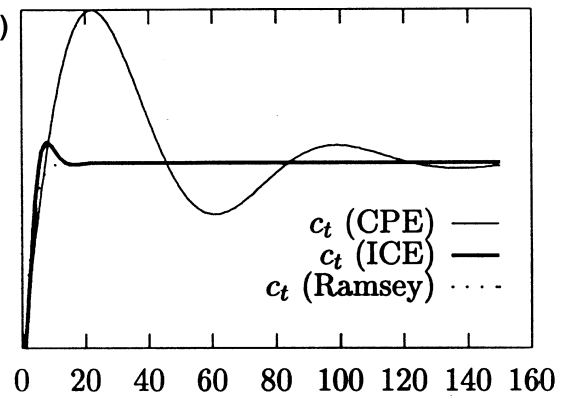

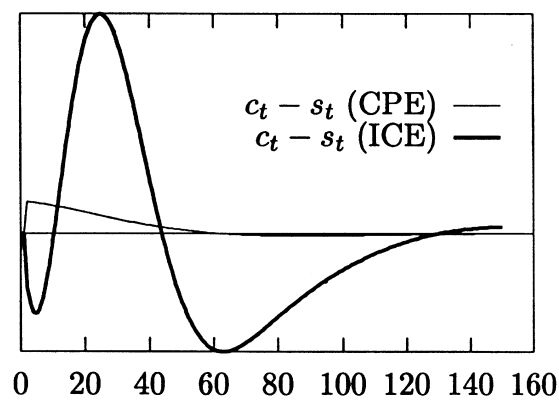
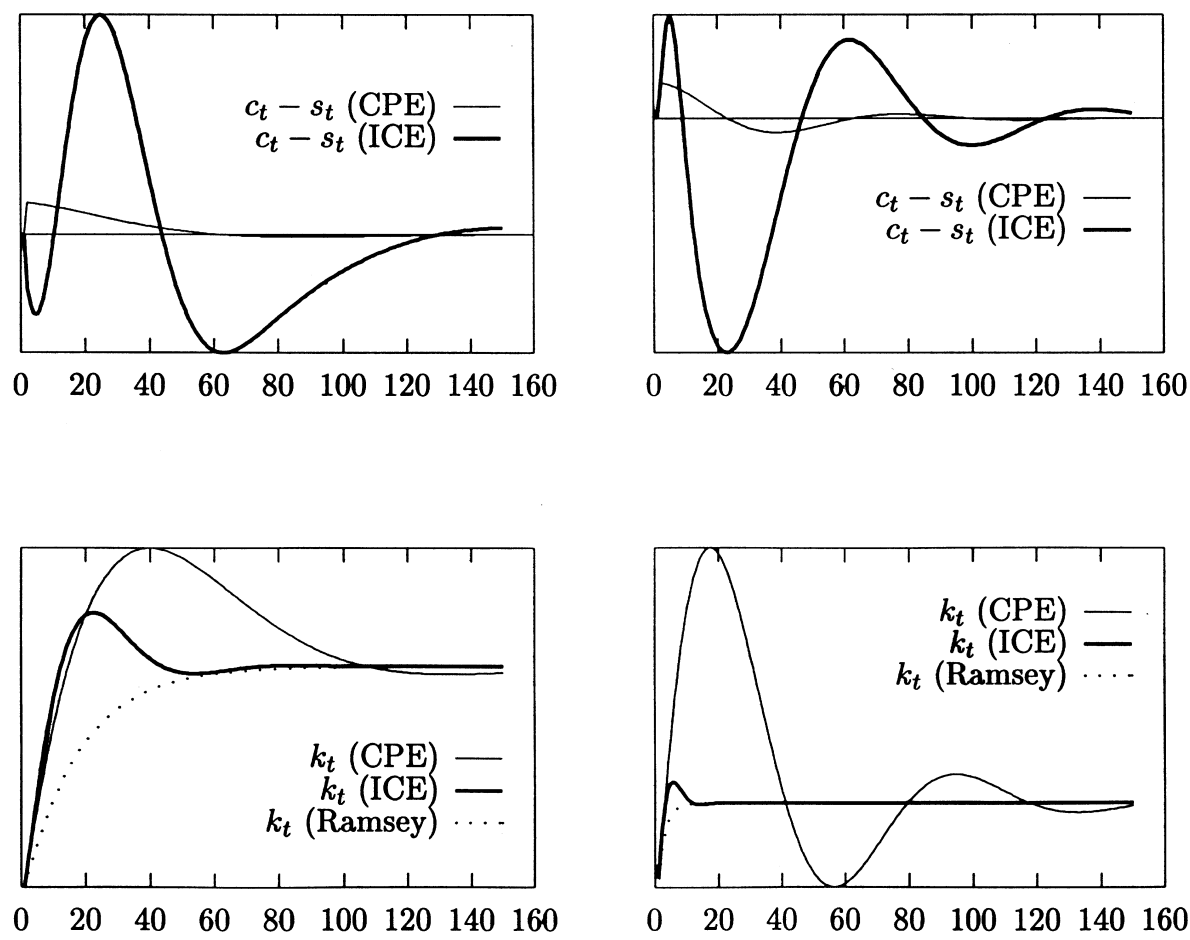

Fig. 4. Permanent rise in productivity. (a) $\rho=5, \theta=0.99$; (b) $\rho=100, \theta=0.8$.

$$
s_{t+1}=\max \left[s_{t}, c_{t}\right]
$$

and is no longer differentiable. However, it is possible to derive an interesting result by using Eq. (19) and by taking its limit when $\rho \rightarrow \infty$. Indeed,

$$
\lim _{\rho \rightarrow \infty}\left(1 / 2 s_{t}^{\rho}+1 / 2 c_{t}^{\rho}\right)^{1 / \rho}=\max \left[s_{t}, c_{t}\right]
$$


Proposition 4. If norms are built on the basis of the best previous experience, the economy displays path dependency.

Proof: We linearize the dynamic system with Eq. (19) around its steady state. We compute the eigenvalues algrebrically. ${ }^{15}$ We then take their limit as $\rho \rightarrow \infty$. The eigenvalues tend to $[1 / \theta, 1,1 / \theta, 1]$

In this framework, reported satisfaction depends on the whole history, including the initial level of norms $\underline{s}$. This case provides interesting elements for explaining international differences in reported satisfaction.

\subsection{Deterministic technical progress}

Technological improvement in form of deterministic labor-saving technical progress is absent from the model. ${ }^{16}$ As is known, technological improvement can coexist with a very special type of utility function in a standard optimal growth model. The introduction of a social norm in that case does not allow getting rid of a restriction on the utility function, but this restriction is different and bears both on the utility function and on the accumulation rule of social norms. Following King et al. (1990), technological improvement can coexist with a balanced growth path if the ratio $u_{1}\left(c_{t}, s_{t}\right) / u_{1}\left(c_{t+1}\right.$, $s_{t+1}$ ) is constant over time (i.e. marginal utility grows at a constant rate). This holds as long as

$$
\frac{u_{11}\left(c_{t}, s_{t}\right) c_{t}}{u_{1}\left(c_{t}, s_{t}\right)}+\left[n_{1}\left(s_{t-1}, c_{t-1}\right) \frac{s_{t}}{c_{t}}+n_{2}\left(s_{t-1}, c_{t-1}\right)\right] \frac{u_{12}\left(c_{t}, s_{t}\right) c_{t}}{u_{1}\left(c_{t}, s_{t}\right)}
$$

is the same for all $t$. Notice that the first term of this expression is the standard coefficient of relative risk aversion. When $u_{12}=0$, there is no effect of norms on marginal utility, and we face the standard constraint that the coefficient of relative risk aversion is independent of the level of consumption. When $u_{12}$ is different from 0 , the restriction is less trivial. With a CRRA utility function, this is verified in the simple example of Ferson and Constantinides (1991) in which $u=\left(c_{t}-\gamma c_{t-1}\right)^{1-\alpha 17}$. More interestingly, the CARA utility function of the example is made compatible with technological improvement by the introduction of social norms (which is not in the standard model as the relative risk aversion depends on consumption) if the accumulation rule is $s_{t+1}=c_{t}$.

\footnotetext{
${ }^{15}$ The detailed computations are available from the author upon request.

${ }^{16}$ It would be interesting to study the role of negative taste externalities in a model in which endogenous growth is made possible by a positive technological externality. The formal treatment would probably be similar to the one in growth models with pollution, see Michel and Rotillon (1995).

${ }^{17}$ In that case, $u_{11} c_{t} / u_{1}=-\alpha c_{t} /\left(c_{t}-\gamma c_{t-1}\right), n_{1}=0, n_{2}=\gamma, u_{12} c_{t} / u_{1}=\alpha c_{t} /\left(c_{t}-\gamma c_{t-1}\right)$ and all these terms are constant when $c_{t} / c_{t-1}$ is constant.
} 


\section{Policy implications}

The fact that satisfaction can be fully "relative" in our framework does not imply that nothing can be done to improve the welfare of the citizens. Contrary to what is exposed in Veenhoven (1991) and Veenhoven (1994), the introduction of relativity does not necessarily imply an ascetic view of the world and the rejection of the welfare state. Indeed, even in the extreme case of Proposition 1 it is possible to set up Paretoimproving policies. Such policies should tackle the taste externality and change the relative prices in order to make the individual consumer choose the first best solution. ${ }^{18}$

Studies of optimal taxes when consumers are interested in relative income (or status) have been carried out by Boskin and Sheshinski (1978) and Layard (1980). They conclude that the concern for relative income always leads to an increase in the optimal marginal tax rate on income with respect to the case of sole concern of absolute income. Our framework differs from these studies in two important aspects. First, we consider a general equilibrium model, linking savings and capital accumulation to relativity in satisfaction. Second, we have essentially shown the dynamic aspect linked to the norm-achievement gap model. This implies that we are able to treat the optimal dynamic path for taxes and, in particular, the optimal tax response in the face of exogenous shocks. The use of public spending will also be developed.

\subsection{Decentralization of the optimal growth path}

Considering the optimal growth path of the modified golden rule type, we study how a government can decentralize the first-best solution in order to make people internalize the effect of the taste externality. Clearly, at steady state, the outcome of the decentralized economy coincides with the one of the centrally planned economy. During the adjustment process however, prices must be set by the authorities so that private decisions based on these prices incorporate the effect of the endogeneously changing tastes. In order to bring consumers to choose the first-best solution, the shadow price of capital should satisfy:

$$
\mu_{t}=\mu_{t}^{*}+\lambda_{t}^{*} n_{2}\left(c_{t}^{*}, s_{t}^{*}\right) .
$$

Assuming that the government temporarily taxes the return to capital at a rate $x_{t}$ and remits the proceeds in a lump-sum fashion to the private sector, the decentralization of the first-best solution can be achieved if $x_{t}$ satisfies: $^{19}$

$$
\theta \mu_{t+1}\left(1+r_{t}\left(1-x_{t}\right)\right)=\mu_{t}^{*}+\lambda_{t}^{*} n_{2}\left(c_{t}^{*}, s_{t}^{*}\right) \text {. }
$$

In order to illustrate the use of Eq. (20) we have computed the optimal path of taxes for the simulation presented in the first panel of Fig. 4 (permanent rise in productivity, with

\footnotetext{
${ }^{18} \mathrm{~A}$ similar argument is proposed by Frank (1989) in the case of positional goods: as consumers do not take positional externalities into account in their decision process, they consume such commodities more intensely than society as a whole would have chosen. "A tax on positional consumption should be attractive to economists for the same reason that a tax on pollution is attractive." (Frank, 1989).

${ }^{19}$ Although it is not often possible to compute such dynamic optimal taxes, see Stern (1992), our model exhibits the interesting property that the use of a single tax rate is sufficient to bring about the first best solution.
} 


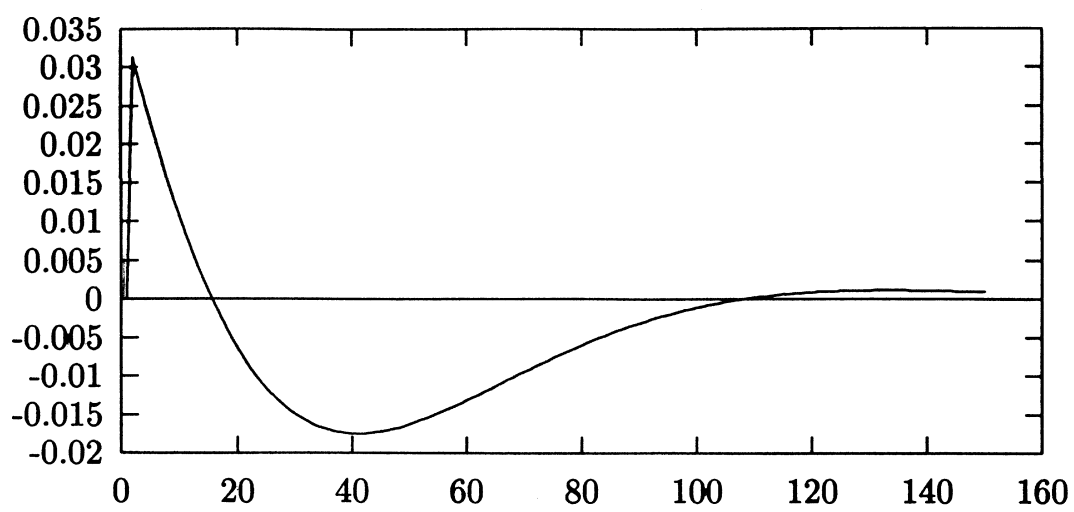

Fig. 5. Optimal tax rate facing a permanent rise in productivity $(\rho=5, \theta=0.99)$.

$\rho=5$ and $\theta=0.99$ ). The result is presented in Fig. 5. It appears that it is optimal for the government to tax the return to capital just after the positive shock, making the consumption profile through time less steep than in the ICE case without taxes. After some periods, however, it is optimal to subsidize capital so as to keep high income and consumption levels as long as possible, and to amplify the medium term effect of the positive shock. Doing so, the individual's choices under competitive markets will coincide with the outcome of the centrally planned economy. In the long-run, the optimal tax rate is zero as both steady-states coincide. The correction of externalities by means of taxation is necessary only during the (long lasting) adjustment process.

When agents have a lower discount factor (they are more "myopic"), the simulations presented in Fig. 4 show that it is optimal to have long lasting oscillations in consumption. In that case, it is optimal for the government to generate more fluctuations than the ones resulting from the functioning of the decentralized economy in view of technological shocks. ${ }^{20}$

To conclude, the optimal tax policy is, to some extent, counter-cyclical, as a positive shock should be followed by an increase in taxes. This is qualified by the fact that, in the medium-run, the optimal tax schedule has to be used to generate the typical asymmetric oscillations described in the path of the central planner.

\subsection{Government spending}

Let us suppose that the government is consuming resources $g_{t}$ and paying for them with lump-sum taxes such that the government budget is balanced at every moment. In that case, Eq. (1) becomes

$$
c_{t} \leq f\left(k_{t}\right)+(1-\delta) k_{t}-k_{t+1}-g_{t} .
$$

\footnotetext{
${ }^{20}$ To study the optimal tax policy when norms are almost formed on the basis of the best previous experience, we have also computed a simulation with a value for $\rho$ of 150 (with $\theta=0.99$ ). As shown before, this increases substantially the "optimal degree of sluggishness". In that case the counter-cyclical part of the policy is shortened and optimal subsidies maintain consumption above its long-run level over a very long period.
} 
and the budget constraint of the individual households is:

$$
c_{i t}=\left(1+r_{t}\right) b_{i t}+w_{t}-b_{i t+1}-g_{t}
$$

The rest of the model is modified accordingly. In the Ramsey model with a CARA utility function such as Eq. (18), permanent changes in public spendings have no effect on capital accumulation (see Blanchard and Fischer, 1989). Contrarily, it turns out here that permanent changes in public spending may have substantial transitory effects on the stock of capital (Fig. 6). For instance, in the case of a rise in public spendings and hence in lump-sum taxes, households consume their savings in order to obtain a slow downward adjustment of consumption. They have difficulties to adjust to their new standard of living.

In the face of such permanent shocks, the norm-achievement gap and therefore instantaneous satisfaction fluctuates before reaching the new steady state. The corresponding reported levels of satisfaction are not one-to-one related to the level of consumption. This is in line with the fact the fluctuations in the percentage of those who said they were very satisfied do not seem related to changes in wealth and/or consumption.

\subsection{Other policies}

The above results depend of course on the traditional assumption that government spending does not affect individuals' utility directly. It could be interesting to develop the same kind of model with a direct effect of government spendings on utility including possibly some habituation mechanism, allowing potential cross effects with the norms derived from private consumption. An example of the positive role of government spending on externalities is provided by $\mathrm{Ng}$ (1987) in a static framework: the external cost of the resources used to produce private goods which are imposed on others through relative-income effects no longer exists in the case of public expenditure on pure public goods. The production of public goods is thus a mean to reduce the inter-individual externalities. An extension of this to a dynamic setting is left for future research.

The framework developed here illustrates that the introduction of norms in the basic
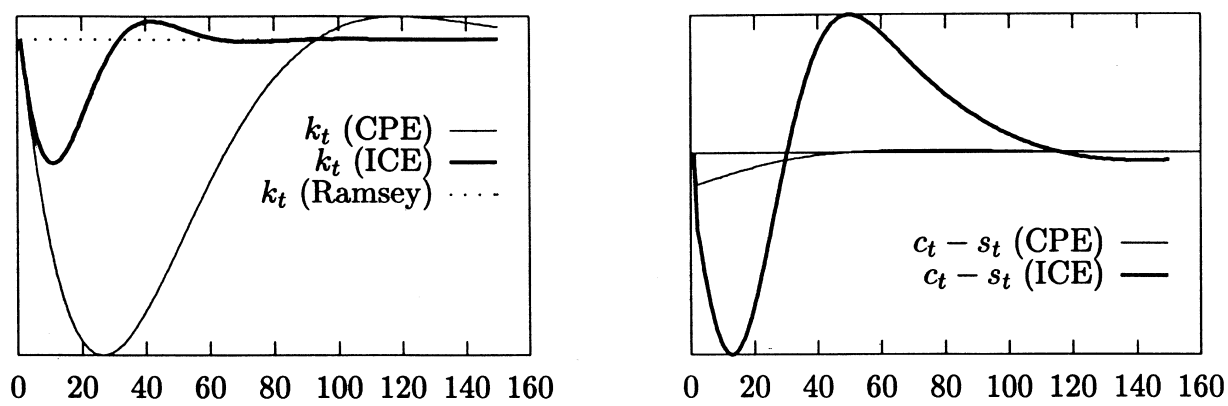

Fig. 6. Permanent rise in government spendings. 
Ramsey model may substantially change its properties in the face of exogenous shocks. A similar framework could be used to re-evaluate some properties of the dynamic general equilibrium models of growth. For instance, concerning the debate on the effectiveness of automatic stabilizers in RBC models, the welfare gains of cyclical stabilization in standard models are largely dominated by steady state welfare losses (see Hairault et al., 1995 and Lucas, 1987). How is this affected by the fact that steady-state welfare may no longer depend on consumption?

Finally, Layard (1980) suggests to alter utility functions in order to reduce the importance of externalities. Education policies could play a role so as to make people more altruistic and less concerned about their status. ${ }^{21}$ In order to analyse such policies, it is necessary to explicitly introduce human capital to the model (or, at least, leisure) and to assume that the function describing how norms are built depends either on the level of human capital or on the time spent on leisure.

\section{Conclusion}

In this paper, we build a growth model in adhesing to the facts that (i) international differences in satisfaction are very small and are almost unrelated to economic prosperity and that (ii) despite continually rising prosperity, there are considerable fluctuations in the percentage of those who say they are very satisfied. We extend the standard Ramsey model stressing the role of relativity and habituation in the utility function. We assume that things are judged by the extent to which they depart from social norms, that norms are based on past experience and that, gradually, the most salient events will cease to have an impact as they themselves are absorbed into the new baseline against which further events are judged. A special case of the model is when comparisons are made with respect to the best previous experience. Our framework displays interesting properties compared to the ones of the standard Ramsey model.

As norms reflect a society's standard-of-living and as each individual does not internalize the effect of his purchases of goods on social norms and thus on future tastes, a taste externality is introduced. Thus, the intertemporal competitive equilibrium is sub-optimal and differs from the centrally planned one.

The intertemporal competitive equilibrium with norms may display oscillatory behaviour if a rise in norms sufficiently increases the desire for consumption. However, the steady state is the same as in the Ramsey model, the Modified Golden Rule (MGR) holds. Moreover, we derive a sufficient condition on preferences for a uniformly maintained increase in consumption not to affect satisfaction at steady state, in which case the model is no longer in contradiction to the facts mentioned above.

Under reasonable conditions, the steady state of the centrally planned equilibrium in terms of consumption and capital is the same as in the Ramsey model, so that the MGR is satisfied and relativity and habituation only play a role in the dynamics of

\footnotetext{
${ }^{21}$ The effect of education on the norm-achievement gap is not straightforward, however, as some empirical studies show that the positive effect of eduction on satisfaction can be offset by the fact that education may lead to higher aspirations and, hence, frustrations (see e.g. Woittiez and Theeuwes, 1995).
} 
consumption and capital. In that case shocks to technology may induce long lasting endogenous oscillations in the main economic variables. It is also possible that the first best solution be characterized by satiation. In that case, the MGR does not hold in general, the planner is indifferent between accepting and rejecting a marginal increment in consumption. The resource constraint of the economy is not binding.

If norms are built on the basis of the best previous experience, the economy displays path dependency. Therefore, reported satisfaction levels depend on the whole history, including the initial level of social norms. This case provides interesting elements for explaining international differences in reported satisfaction.

The government can decentralize the optimal growth path by raising temporary taxes or subsidies on capital. Simulations show that it can be optimal for this government to have a counter-cyclical policy and, in the medium-run, to generate more fluctuations than the ones resulting from the functioning of the decentralized economy in view of exogenous shifts in the parameters.

Finally, changes in public spending may have substantial transitory effects on the capital stock and on instantaneous satisfaction. The corresponding reported level of satisfaction are not related one-to-one to the level of consumption, which is not in contradiction to the fact that fluctuations in the percentage of those who say they are very satisfied seem unrelated to changes in wealth and/or consumption.

This paper opens at least two possibilities for further research: formulating relative consumption hypothesis in an endogenous growth model and characterizing the social norm function that is compatible with the existence of a steady state.

\section{Acknowledgements}

I am grateful to two anonymous referees and to P. Beguin, A. d'Autume, F. Collard, S. Deneulin, J.P. Drugeon, M. Germain, J.P. Laffargue, O. Licandro, P. Michel, G. Pfann, P. Van Parijs and D. Weiserbs for useful discussions. The financial support of the PAC programme 93/98-162 of the Ministry of Scientific Research (French Speaking Community, Belgium) is gratefully aknowledged.

\section{Appendix A}

\section{The dynamics of the decentralized equilibrium}

Let us define $A=-u_{11} / u_{1}$, in which all derivatives are taken at steady state. Linearizing the system around the steady state leads to:

$$
\left[\begin{array}{c}
c_{t+1}-\tilde{c} \\
k_{t+1}-\tilde{k} \\
s_{t+1}-\tilde{s}
\end{array}\right]=\left[\begin{array}{ccc}
1-\frac{\theta f_{11}}{A}-\frac{n_{1} u_{12}}{u_{11}} & \frac{n_{11}}{A} & \frac{\left(1-n_{2}\right) u_{12}}{u_{11}} \\
-1 & \frac{1}{\theta} & 0 \\
n_{1} & 0 & n_{2}
\end{array}\right]\left[\begin{array}{c}
c_{t}-\tilde{c} \\
k_{t}-\tilde{k} \\
s_{t}-\tilde{s}
\end{array}\right]
$$


The eigenvalues are

$$
\begin{gathered}
\left\{-\frac{\psi}{3}+\frac{\sqrt[3]{2}\left(\psi^{2}-3 \kappa\right)}{3 \chi}+\frac{\chi}{3 \sqrt[3]{2}}, \quad-\frac{\psi}{3}-\frac{(1+i \sqrt{3})\left(\psi^{2}-3 \kappa\right)}{32^{2 / 3} \chi}-\right. \\
\left.\frac{(1-i \sqrt{3}) \chi}{6 \sqrt[3]{2}}, \quad-\frac{\psi}{3}-\frac{(1-i \sqrt{3})\left(\psi^{2}-3 \kappa\right)}{32^{2 / 3} \chi}-\frac{(1+i \sqrt{3}) \chi}{6 \sqrt[3]{2}}\right\}
\end{gathered}
$$

where

$$
\begin{aligned}
& \xi=\left(-n_{2}+n_{1} \frac{u_{12}}{u_{11}}\right) \frac{1}{\theta} \\
& \psi=\frac{-1}{\theta}-1+\frac{\xi}{\theta}+\frac{f_{11} \theta}{A} \\
& \kappa=\frac{1}{\theta}-\xi-\frac{\xi}{\theta}+\frac{f_{11} n_{2} \theta}{A} \\
& \chi=\sqrt[3]{-27 \xi-2 \psi^{3}+9 \psi \kappa+3 \sqrt{3} \sqrt{27 \xi^{2}+4 \xi \psi^{3}-18 \xi \psi \kappa-\psi^{2} \kappa^{2}+4 \kappa^{3}}}
\end{aligned}
$$

Special case $1 . u_{12}=0$. The eigenvalues are:

$$
\left\{n_{2}, \frac{1+\theta}{2 \theta}-\frac{f_{11} \theta}{2 A} \pm \sqrt{\frac{-1}{\theta}+\left(\frac{1+\theta}{2 \theta}-\frac{f_{11} \theta}{2 A}\right)^{2}}\right\}
$$

Special case 2. $n_{2}=1$. The eigenvalues are:

$$
\left\{1, \frac{1+\theta}{2 \theta}-\frac{u_{12} n_{1}}{2 A}-\frac{f_{11} \theta}{2 A} \pm \sqrt{\frac{-1}{\theta}+\left(\frac{1+\theta}{2 \theta}-\frac{u_{12} n_{1}}{2 A}-\frac{f_{11} \theta}{2 A}\right)^{2}}\right\}
$$

\section{Appendix B}

\section{Simulation method}

The resolution of the dynamic model relies on a Newton-Raphson relaxation method proposed by Boucekkine (1995) and Laffargue (1990) for solving dynamic nonlinear models with perfect foresight. The general problem is to solve a system of finite difference equations with initial and terminal conditions. Approximating the infinite horizon by a finite one, (that means that the transversality conditions on anticipated variables are replaced by the steady-state values of these variables at the end of the horizon of simulation) the complete system has as many equations as the number of equations at each period multiplied by the simulation horizon plus the initial and terminal conditions: 


$$
\left\{\begin{array}{ccc}
z_{0}^{1} & = & z_{\text {init }} \\
f\left(z_{1}, z_{0}^{1}, z_{2}^{2}, \kappa\right) & = & 0 \\
\vdots & \vdots & \vdots \\
f\left(z_{T}, z_{T-1}^{1}, z_{T+1}^{2}, \kappa\right) & = & 0 \\
z_{T+1}^{2} & = & z_{\text {steady state }}^{2}
\end{array}\right.
$$

where $z_{t}=\left(z_{t}^{2}, z_{t}^{1}\right)$ is the vector of endogenous variables at $t$, including the predetermined variables $\left(z_{t}^{1}\right)$, the non-predetermined variables $\left(z_{t}^{2}\right) . f$ is a vector function representing our dynamic model and $\kappa$ is the vector of exogenous variables and parameters. The system ( $\mathrm{S}$ ) is solved using a Newton-Raphson algorithm in which the Newton-Raphson improvement at each iteration is computed by triangulation (instead of inversion) of the matrix of the first derivatives of the system. As Boucekkine (1995) shows, this method allows characterisation of the nature of the dynamics of the model (explosivity, saddle-point trajectory or infinite number of stable solutions) without having to linearise it and to compute the eigenvalues of the linearised system. In particular, it is easy to determine whether the convergence of the algorithm is due to the existence of saddle-point trajectory or not. Indeed, the algorithm is characterised by an explosivity property in the case where an infinity of stable solutions exist. This explosivity property is in fact common to all convergent relaxation methods. The explosive behaviour is put forward by a simple numerical procedure relying on the initialisation of the relaxation. Initialising the relaxation with values slightly different from the steady state leads to an explosive behaviour at the first Newton-Raphson improvement.

\section{References}

Abel, A., 1990. Asset prices under habit formation and catching up with the Joneses. American Economic Review Paper and Proceedings 80, 38-42.

Argyle, M., 1987. The Psychology of Happiness. Methuen, London.

Barro, R., Sala-I-Martin, X., 1995. Economic Growth. McGraw-Hill, New York.

Becker, G., 1996. Accounting for Tastes. Harvard University Press, Cambridge, MA.

Blanchard, O., Fischer, S., 1989. Lectures on Macroeconomics. MIT, Cambridge, MA.

Boskin, M., Sheshinski, E., 1978. Optimal redistributive taxation when individual welfare depends upon relative income. Quarterly Journal of Economics 92, 589-601.

Boucekkine, R., 1995. An alternative methodology for solving non-linear forward-looking models. Journal of Economic Dynamics and Control 19, 711-734.

Brickman, P., Coates, D., Janoff-Belman, R., 1978. Lottery winners and accident victims: Is happiness relative? Journal of Personality and Social Psychology 36, 917-927.

Campbell, J., Cochrane, J., 1995. By Force of Habits: A Consumption-based Explanation of Aggregate Stock Market Behavior. Working Paper, NBER.

Cantril, H., 1965. The Pattern of Human Concerns. Rutgers University Press, New Brunswick.

Cass, D., 1965. Optimum growth in an aggregative model of capital accumulation. Review of Economic Studies 32, 233-240.

Clark, A., Oswald, A., 1996. Satisfaction and comparison income. Journal of Public Economics 61, 359-381. de la Croix, D., 1996. The dynamics of bequeathed tastes. Economics Letters 51, 89-96.

de la Croix, D., Michel, P., 1997. Optimal Growth When Tastes are Inherited. Journal of Economic Dynamics and Control, forthcoming.

de la Croix, D., Palm, F., Pfann, G., 1996. A dynamic contracting model for wages and employment in three European economies. European Economic Review 40, 429-448. 
Duesenberry, J., 1949. Income, Saving, and the Theory of Consumer Behavior. Harvard University Press, Cambridge, MA.

Easterlin, R., 1974. Does economic growth improve the human lot? Some empirical evidence. In: David, P., Reder, M. (Eds.), Nations and Households in Economic Growth. Academic Press.

Easterlin, R., 1995. Will raising the incomes of all increase the hapiness of all? Journal of Economic Behaviour and Organization 27, 35-36.

Elster, J., 1979. Ulysses and the Sirens: Studies in Rationality and Irrationality. Cambridge University Press, Cambridge, MA.

European Commission. Euro-barometer, various issues.

Ferber, R., 1973. Consumer economics, a survey. Journal of Economic Literature 11, 1303-1342.

Ferson, W., Constantinides, G., 1991. Habit persistence and durability in aggregate consumption. Journal of Financial Economics 29, 199-240.

Frank, R., 1989. Frames of references and the quality of life. American Economic Review, papers and proceedings $79,80-85$.

Frank, R., Hutchens, R., 1993. Wages, seniority, and the demand for rising consumption profiles. Journal of Economic Behavior and Organization 21, 251-276.

Hairault, J.-O., Langot, F., Portier, F., 1995. On the Effectiveness of Automatic Stabilizers: A Macroeconomic General Equilibrium Approach. Working Paper, CEPREMAP.

Helson, H., 1964. Adaptation-level Theory: An Experimental and Systemic Approach to Behavior. Harper and Row, New York.

King, R., Plosser, C., Rebelo, S., 1990. Production Growth and Business Cycles: Technical Appendix. University of Rochester.

Kotowitz, Y., Portes, R., 1974. The tax on wage increases. Journal of Public Economics 3, 112-132.

Laffargue, J.-P., 1990. Résolution d'un modèle macroéconomique à anticipations rationnelles. Annales d'Economie et de Statistisque 17, 97-119.

Layard, R., 1980. Human satisfactions and public policy. Economic Journal 90, 737-750.

Lucas, R., 1987. Models of the Business Cycles. Basil Blackwell, Cambridge MA.

Michalos, A., 1980. Satisfaction and happiness. Social Indicators Research 8, 385-422.

Michel, P., Rotillon, G., 1995. Disutility of pollution and endogenous growth. Environmental and Resource Economics 6, 279-300.

Ng, Y.-K., 1978. Economnic growth and social welfare: the need for a complete study of happiness. Kyklos 31 , $575-587$.

$\mathrm{Ng}$, Y.-K., 1980. Money and happiness: first lesson in eudaimonology? Kyklos 33, 161-163.

$\mathrm{Ng}$, Y.-K., 1987. Relative-income effects and the appropriate level of public expenditures. Oxford Economic Papers 39, 293-300.

$\mathrm{Ng}$, Y.-K., Wang, J., 1993. Relative income, aspiration, environmental quality, individual and political myopia: why may the rat-race for material growth be welfare-reducing? Mathematical Social Sciences 26, 3-23.

Ramsey, F., 1928. A mathematical theory of savings. Economic Journal 38, 543-559.

Romer, P., 1989. Capital accumulation in the theory of long-run growth. In: Barro, R. (Ed.), Modern Business Cycle Theory. Basil Blackwell, Cambridge MA.

Ryder, H., Heal, G., 1973. Optimal growth with inter-temporally dependent preferences. Review of Economic Studies 40, 1-31.

Scitovsky, T., 1976. The Joyless Economy. Oxford University Press, Oxford, UK.

Silver, M., 1980. Money and happiness: towards "eudaimonology". Kyklos 33, 157-160.

Stern, N., 1992. From the static to the dynamic: some problems in the theory of taxation. Journal of Public Economics 47, 273-297.

Veenhoven, R., 1991. Is happiness relative? Social Indicators Research 24, 1-34.

Veenhoven. R., 1993. Happiness in Nations: Subjective Appreciation of Life in 56 Nations 1946-1992. Erasmus University Rotterdam.

Veenhoven, R., 1994. Is happiness a trait - tests of the teory that a better society does not make people any happier. Social Indicators Research 32, 101-160.

Wan, H., 1970. Optimal saving programs under intertemporally dependent preferences. International Economic Review 11, 521-547.

Woittiez, I., Theeuwes, J., 1995. Well-being and Labour Market Status. Working Paper, Tinbergen Institut. 